\title{
Echolocation clicks of free-ranging Cuvier's beaked whales (Ziphius cavirostris)
}

\author{
Walter M. X. Zimmer ${ }^{\mathrm{a})}$ \\ NATO Undersea Research Centre, V.le San Bartolomeo 400, 19138 La Spezia, Italy
}

Mark P. Johnson, Peter T. Madsen, and Peter L. Tyack

Woods Hole Oceanographic Institution, Woods Hole, Massachusetts 02543

(Received 2 December 2004; revised 19 March 2005; accepted 24 March 2005)

\begin{abstract}
Strandings of beaked whales of the genera Ziphius and Mesoplodon have been reported to occur in conjunction with naval sonar use. Detection of the sounds from these elusive whales could reduce the risk of exposure, but descriptions of their vocalizations are at best incomplete. This paper reports quantitative characteristics of clicks from deep-diving Cuvier's beaked whales (Ziphius cavirostris) using a unique data set. Two whales in the Ligurian Sea were simultaneously tagged with sound and orientation recording tags, and the dive tracks were reconstructed allowing for derivation of the range and relative aspect between the clicking whales. At depth, the whales produced trains of regular echolocation clicks with mean interclick intervals of $0.43 \mathrm{~s}( \pm 0.09)$ and $0.40 \mathrm{~s}( \pm 0.07)$. The clicks are frequency modulated pulses with durations of $\sim 200 \mu \mathrm{s}$ and center frequencies around $42 \mathrm{kHz},-10 \mathrm{~dB}$ bandwidths of $22 \mathrm{kHz}$, and $Q_{3 \mathrm{~dB}}$ of 4 . The sound beam is narrow with an estimated directionality index of more than $25 \mathrm{~dB}$, source levels up to $214 \mathrm{~dB}_{\mathrm{pp}} r e: 1 \mu \mathrm{Pa}$ at $1 \mathrm{~m}$, and energy flux density of $164 \mathrm{~dB}$ re: $1 \mu \mathrm{Pa}^{2} \mathrm{~s}$. As the spectral and temporal properties are different from those of nonziphiid odontocetes the potential for passive detection is enhanced. (C) 2005 Acoustical Society of America. [DOI: 10.1121/1.1910225]
\end{abstract}

PACS numbers: 43.80.Ka [WA]

Pages: $3919-3927$

\section{INTRODUCTION}

Since the basic characterization of echolocation clicks of bottlenose dolphins by Au et al. (1974), it has been known that toothed whales are capable of producing highly directional ultrasonic clicks with source levels of more than $220 \mathrm{~dB}_{\mathrm{pp}}$ re: $1 \mu \mathrm{Pa}$ at $1 \mathrm{~m}$. During 30 years of studies on captive animals ( $\mathrm{Au}, 1993)$, and increasingly during the last decade on free-ranging animals (Møhl et al., 1990; Au and Herzing, 2003; Schotten et al., 2003; Au et al., 2004; Madsen et al., 2004), it has become apparent that toothed whale species produce a diverse range of biosonar signals (Au, 1997). Overall, toothed whale sonar signals can be divided into the low-output, monochromatic, high frequency pulses of Phocoena and Cephalorhynchus and the shorter more broadband and higher source level clicks of most dolphin species (Au, 1997). A third group, sperm whales, produces multi-pulse sonar clicks, dominated by a single highly directional pulse centered around $15 \mathrm{kHz}$ with source levels of more than $230 \mathrm{~dB}_{\mathrm{rms}} r e: 1 \mu \mathrm{Pa}$ at $1 \mathrm{~m}$ (Møhl et al., 2003; Zimmer et al., 2005).

Information on the characteristics of sonar signals from a major group of some 20 species of deep-diving toothed whales, the beaked whales (Ziphiidae) (Rice, 1998), is sparse. There are a few recordings of sounds from stranded whales (Caldwell and Caldwell, 1971; Lynn and Reiss, 1992; Marten, 2000) that may not be representative of the sounds of healthy, free ranging whales. Data from free-ranging beaked whales in offshore habitats is limited to a few spe-

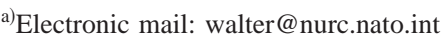

cies, including Hyperoodon (Hooker and Whitehead, 2002) and Berardius (Dawson et al., 1998).

This lack of information is especially serious for Cuvier's beaked whale (Ziphius cavirostris), as this species appears to be highly sensitive to anthropogenic noise as demonstrated by several mass strandings during and after military sonar exercises (Simmonds and Lopez-Jurado, 1991; Frantzis, 1998; Jepson et al., 2003). Quantitative data on how Ziphius produce and use sound may help in understanding the sensitivity of this species to anthropogenic sound and will be crucial for the development of passive identification and monitoring techniques, to minimize the impact of human activity.

Frantzis et al. (2002) analyzed about $5 \mathrm{~h}$ of recordings acquired off SW Crete in proximity to Ziphius. They reported the presence of click trains with average click duration of $1.08 \mathrm{~ms}$ and with click energy concentrated in a narrow peak between 13 and $17 \mathrm{kHz}$. The average interclick interval was $0.44 \mathrm{~s}$, and clicking was frequently interrupted by short pauses. Frantzis et al. (2002) did not detect click sequences with elevated click rates and speculated that the whales may use visual cues in the final stages of prey capture.

Recently, Johnson et al. (2004) reported data from the successful tagging of four beaked whales [two Blainville's beaked whales (Mesoplodon densirostris) and two Ziphius] demonstrating echoes from prey recorded after the whales produced ultrasonic clicks for echolocation. Like other odontocetes and bats, Ziphius produce high repetition click trains (so-called buzzes) during the final stages of prey capture (Johnson et al., 2004). The intervals between regular clicks for Ziphius were close to $0.4 \mathrm{~s}$ and the clicks were $\sim 175 \mu \mathrm{s}$ 
long with a relatively flat spectrum from $30 \mathrm{kHz}$ up to the 48 $\mathrm{kHz}$ Nyquist cutoff frequency of the acoustic recording system in use. No information could be given on the highfrequency limit of click energy or the radiation pattern of the clicks. Such data are necessary to study the biosonar performance of this little known species and to provide a quantitative basis for evaluating passive acoustic detection and monitoring.

In this paper we report estimates of the source characteristics of Ziphius echolocation clicks using the novel approach of two tagged whales recording each other. We provide the first estimates of the source level, directivity index, and spectral properties of Ziphius clicks, which are shown to differ significantly from those produced by non-ziphiid toothed whales described so far, suggesting a strong potential for passive acoustic monitoring.

\section{METHODS}

The results in this paper are based on three data sets from sea trials performed in the Ligurian Sea by the NATO Undersea Research Center (NURC) and the Woods Hole Oceanographic Institution (WHOI) as part of their combined effort to broaden the knowledge on beaked whales to mitigate detrimental effects of human activity.

(1) July 2002 NURC: recordings from a single hydrophone with $384 \mathrm{kHz}$ sampling rate.

(2) June 2004 WHOI: recordings from digital recording tags (DTAG) on two whales in a group of 5 (zc04_161a, zc04_161b). The sampling rate was $96 \mathrm{kHz}$ and the tags remained attached for 9 and $19 \mathrm{~h}$, respectively.

(3) June 2004 WHOI: stereo DTAG recording from a single whale in a group of 4 Ziphius (zc04_179a). The sampling rate was $192 \mathrm{kHz}$ and the tag remained attached for $4 \mathrm{~h}$.

The NURC July 2002 sea trial (Sirena02) took place in an area of underwater canyons known to be inhabited by Ziphius. Following standard oceanographic and biological sampling, and whenever Ziphius were sighted, a hydrophone was deployed to about $80 \mathrm{~m}$ for $1 \mathrm{~h}$ of acoustic recording. The June 2004 WHOI experiment was dedicated to tagging and took place in the same area as the NURC July 2002 sea trial. After sightings of Ziphius, the tagging team slowly approached the whales in a small inflatable boat. A lightweight $5 \mathrm{~m}$ carbon fiber pole was used to deliver the tag. The tag was attached to the whale with a set of four small silicone suction cups that were vented after a programmable time to release the tag from the whale. The tag was then recovered with the aid of a built-in VHF transmitter (Johnson and Tyack, 2003).

\section{A. Instrumentation}

Two acoustic receivers were used to collect the data presented in this paper. The July 2002 NURC sea trial used a single broadband hydrophone $(-3 \mathrm{~dB}$ bandwidth from 1 to $160 \mathrm{kHz}$ ) with a NURC-designed low noise pre-amplifier (spectral electronic noise level $15 \mathrm{~dB} r e: 1 \mu \mathrm{Pa}^{2} / \mathrm{Hz}$ at 50 $\mathrm{kHz}$ ). The hydrophone signal was recorded by a Sony
SIR1000 recorder sampling at $384 \mathrm{kHz}$. The overall clipping level was $140 \mathrm{~dB}_{\text {peak }} r e: 1 \mu \mathrm{Pa}$ and the data were digitized with 16 bit resolution.

The DTAG, a miniature sound and orientation recording tag developed at WHOI, was used during the June 2004 WHOI sea trial. Mono or stereo acoustic data were sampled at 96 or $192 \mathrm{kHz}$ using a 16-bit resolution sigma-delta analog digital converter. The clipping level was set to $181(96 \mathrm{kHz}$ version) and 171 (192 kHz version) $\mathrm{dB}_{\text {peak }} r e: 1 \mu \mathrm{Pa}$. Accelerometers, magnetometers, and a pressure sensor were sampled at $50 \mathrm{~Hz}$ to measure orientation and depth of the tagged whale. Data were stored digitally in up to 6.6 Gbyte of nonvolatile memory (Johnson and Tyack, 2003).

\section{B. Processing}

During deep dives, the dominant sounds in the tag recordings were clicks from the tagged whale and nearby conspecifics. Clicks from the tagged whale and conspecifics can be distinguished spectrally: due to the physical attachment of the tag to the body of the whale there is relatively high coupling of sound energy below $20 \mathrm{kHz}$ from that whale to the tag. This spectral energy is virtually absent in the clicks from conspecifics. Based on these observations, analysis of the recordings proceeded in several steps.

Clicks from each tagged whale were automatically detected and verified by visual inspection of temporal and spectral characteristics, to establish the time of click emission and the interclick interval (ICI) statistics. The position of the tags on the dorsal surface of the whale, behind the sound source, leads to a poor estimate of the spectrum of the clicks in the forward direction. For this reason, the tag recordings were examined for clicks from other whales with ICI and spectral characteristics consistent with far-field Ziphius clicks (Johnson et al., 2004). These were checked individually and the process was repeated for the NURC recording. The result was a set of far-field Ziphius click wave forms with unknown source aspect. Many of these clicks occurred in short sequences of increasing and then decreasing amplitude, presumably due to movement of the clicking whale with respect to the receiver as the whale scanned with a directional sonar beam. Assuming that Ziphius, like all other odontoceti investigated, concentrate sound energy into a forward-directed beam, the highest amplitude clicks were considered to best represent the click wave form within the beam (Møhl et al., 2000; Johnson et al., 2004). These clicks were reserved for spectral analysis.

In addition to the power spectral density, signals were parametrized in terms of energy flux density and mean or center frequency. Energy flux density is estimated by the formula

$$
E=\frac{1}{\rho c} \int_{T_{1}}^{T_{2}}|s(t)|^{2} d t,
$$

where $s(t)$ is the pressure time-series of the click and the integration boundaries $T_{1}$ and $T_{2}$ are determined such that $E$ covers $97 \%$ of the measured signal energy. The term $\rho c$ is the characteristic impedance of the propagation medium, which for water is $\rho c \approx 1.5 \times 10^{6}$ rayl (Lurton, 2002). The 
signal duration is then determined by the time difference between the integration boundaries:

$$
\tau=T_{2}-T_{1} \text {. }
$$

A key parameter used to describe the spectral characteristic is the mean or center frequency of the spectrum, which was estimated by the formula ( $\mathrm{Au}, 1993)$ :

$$
f_{0}=\frac{\int_{-\infty}^{\infty} f|S(f)|^{2} d f}{\int_{-\infty}^{\infty}|S(f)|^{2} d f},
$$

where $S(f)$ is the Fourier transform of signal time series.

Two further processing steps were required to estimate the source level (SL) and directivity index (DI) from the simultaneous tag recordings zc04_161a and b. These tags were applied to two whales swimming within the same group and the tag recordings overlapped for $8 \mathrm{~h}$, spanning four deep dives. Having detected the clicks from each of the tagged whales in the corresponding tag, we examined the tag recordings for clicks emanating from the other tagged whale, i.e., recording B (zc04_161b) was examined for clicks from whale A (zc04_161a) and vice versa. This was achieved by cross-correlating the times of clicks made by one tagged whale with the reception times of conspecific clicks in the other tag recording. The time delays were noted in each direction (i.e., from whale $\mathrm{A}$ to whale $\mathrm{B}$ and from $\mathrm{B}$ to $\mathrm{A}$ ) and the range and clock offset between the tags were estimated.

In order to relate the received level of clicks to the relative position of the clicking whale, the underwater track of each whale was reconstructed. This was achieved by combining the orientations recorded by the tags with swim-speed estimates, and the predicted ranges between the two whales. The orientation of each whale was obtained from the accelerometers and magnetometers in the DTAG (Johnson and Tyack, 2003; Zimmer et al., 2003), corrected for the position of the tag on the body. The orientation of the tag on the whale was estimated from the data by assuming that while the whale is swimming on the surface, the mean pitch and roll are zero and the variance of the roll is minimal. The procedure further assumes that the mean swimming direction is parallel to the body axis. The swim-speed estimator comprised a Kalman filter (Jazwinski, 1970) to fit the pitch angle to the depth profile recorded by the tag. Combining the estimates, the track of each whale, up to integration constants, was obtained by integrating the $(x, y, z)$ components of orientation multiplied by the swim speed. The acoustic ranges were finally used to improve the tracks and to obtain the integration constants.

Knowing the separation and relative orientation of the two whales, it was possible to estimate the elevation and azimuth of each whale with respect to the receiving whale for all clicks. These data were used to calculate the apparent source level (ASL sensu Møhl et al., 2000) as a function of off-axis angle, i.e., the angle between the caudal-rostral axis of the clicking whale and the vector joining the two whales. The transmission loss due to sound propagation between the whales was estimated using spherical spreading and an absorption loss of $10 \mathrm{~dB} / \mathrm{km}$ for a frequency of $40 \mathrm{kHz}$ (Lurton, 2002). Source level (SL) and DI were then obtained by analyzing the shape of the ASL function. In reality, the off-axis angle is relative to the body axis, while the description of the acoustic beam requires knowledge of the acoustic axis (Au et al., 1986). The analysis of the measured ASL function must therefore allow for differences between acoustic and body axes.

As in other cases (Au, 1993; Møhl et al., 2003; Rasmussen et al., 2004; Zimmer et al., 2005), the acoustic beam of odontocetes may be described by a flat circular piston model:

$$
P(x)=P_{0} \frac{2 J_{1}(x)}{x},
$$

with

$$
x=k a \sin \vartheta=2 \pi \frac{a \sin (\vartheta)}{c} f,
$$

where $P_{0}=$ source level, $a=$ piston radius, $c=$ speed of sound, $\vartheta=$ off-axis angle, $f=$ frequency, $J_{1}=$ Bessel function of the first kind.

This model provides a convenient way to parametrize the ASL function using a minimum set of parameters, namely, source level, effective piston radius, frequency, and off-axis angle. The broadband beam pattern, $B(\vartheta)$, can be approximated by integrating $P(x)$ with respect to frequency. A spectrum based weighting function $W(f)$ is used to account for the variation in source level with frequency,

$$
B(\vartheta)=\frac{\int_{-\infty}^{\infty} P^{2}(\vartheta, f) W^{2}(f) d f}{\int_{-\infty}^{\infty} W^{2}(f) d f} .
$$

As will be shown, the power spectrum of Ziphius clicks can be approximated by a Gaussian function, which will be used for the weighting function:

$$
W(f)=\exp \left\{-\frac{1}{2}\left(\frac{f-f_{0}}{b}\right)^{2}\right\},
$$

where $f_{0}$ and $b$ are the center frequency and rms bandwidth, respectively, and obtained by the least-mean-square fit of $W(f)$ to the measured power spectrum.

The directivity index is finally obtained by numeric integration of the modeled broadband beam pattern (Lurton, 2002):

$$
\mathrm{DI}=10 \log \left(\frac{\mathrm{B}(0) \int_{0}^{\pi} \sin \vartheta d \vartheta}{\int_{0}^{\pi} \mathrm{B}(\vartheta) \sin \vartheta d \vartheta}\right) .
$$

The directivity index may be related to the beam width by combining the expression for the $-3 \mathrm{~dB}$ beam width $\Theta$ $=2 \vartheta_{-3 \mathrm{~dB}} \approx 185^{\circ} / \mathrm{ka}$ with the expression for the directivity index $\mathrm{DI} \approx 20 \log (k a)$, which are valid for a circular piston and $k a \gg 1$ (Lurton, 2002), to obtain the following relation:

$$
\Theta \approx 185^{\circ} \times 10^{-\mathrm{DI} / 20} .
$$

\section{RESULTS}

Echolocation clicks from tagged whales and conspecifics were reliably detected in all of the tag recordings. In the double tag data set (zc04_161a and b), clicks made by one of the tagged whales were frequently heard in the other tag, and vice versa, providing sufficient estimates of range to perform 

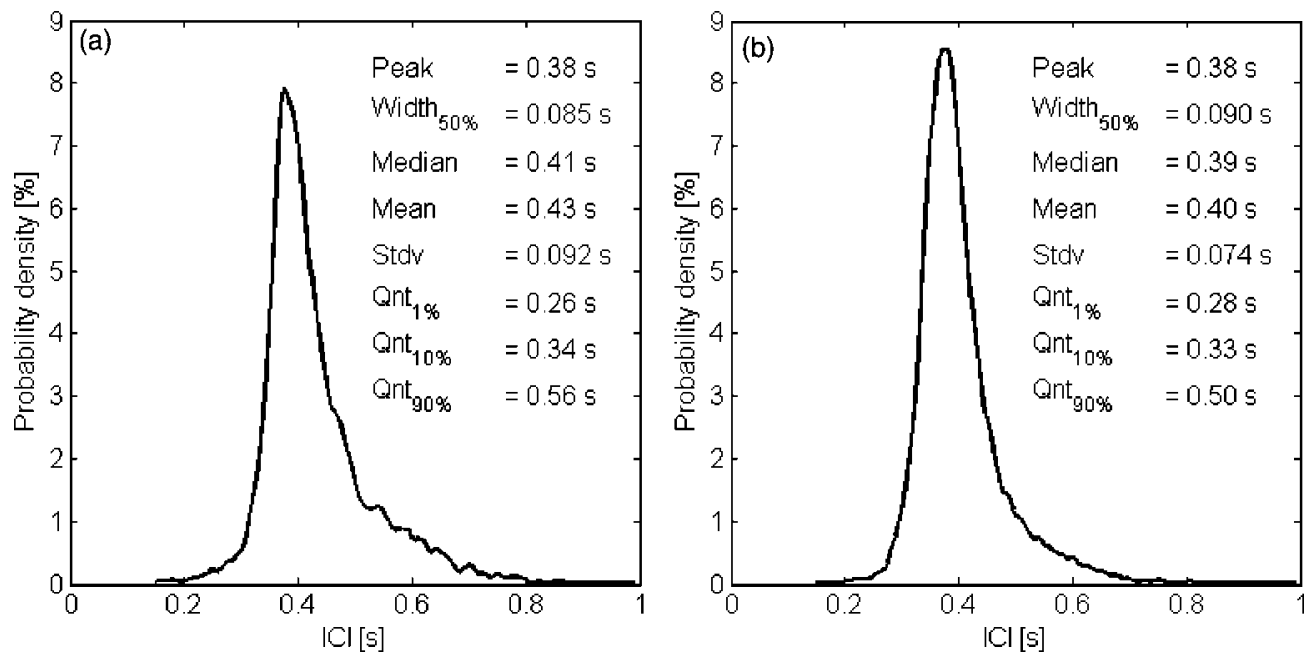

FIG. 1. Probability density function of the inter-click interval (ICI) of both whales. A total of 10736 and 11117 of regular clicks (ICI $>0.15 \mathrm{~s}$ and ICI $<1 \mathrm{~s}$ ) were used for whales A and B, respectively. The bin width for the density function was $0.005 \mathrm{~s}$, and the bins with the largest number of ICIs were 0.38 $\mathrm{s}$ for whales A and B. The density function does not include the ICI of terminal click buzzes with $\mathrm{ICI}<0.15 \mathrm{~s}$ and over extended pauses with resulting ICI $>1 \mathrm{~s}$.

track reconstruction. Far-field Ziphius clicks were also detected in the recording made with the NURC hydrophone.

\section{A. Temporal and spectral characteristics}

Interclick intervals (ICIs) were measured for two whales called whale A and whale B. Figure 1 shows for both whales the probability density function of the ICI over three dives. The estimates do not include the ICI of buzz sounds with ICI $<0.15 \mathrm{~s}$ or the occasional pauses in clicking with ICI values $>1 \mathrm{~s}$. Buzzes are characterized by a significant decrease in source level and consequently the same buzz clicks were not reliably detected on both whales. For whale A, 10736 clicks were analyzed for ICI, yielding a mean ICI of $0.43 \mathrm{~s}$ with a standard deviation of $0.092 \mathrm{~s}$ and a median of $0.41 \mathrm{~s}$. For whale B, 11117 clicks were analyzed for ICI, yielding a mean ICI of $0.40 \mathrm{~s}$ with a standard deviation of $0.074 \mathrm{~s}$ and a median of $0.39 \mathrm{~s}$. Both histograms are asymmetric with a sharp limit on the lower side and softer decay at higher ICI.

Figure 2 shows the time series, power spectrum, and time-frequency spectrogram (short-time Fourier transform with window size of 32 samples, and 31 samples overlap) of a representative far-field Ziphius click from the zc04_179a recording with $192 \mathrm{kHz}$ sampling rate. The effective duration of the click is based on the $97 \%$ energy criteria and is estimated as $\tau=203 \mu \mathrm{s}$ [Eq. (2)]. The spectrogram indicates that the signal is frequency modulated with a half power frequency range starting from $35 \mathrm{kHz}$ and ending around 45 $\mathrm{kHz}$ and with a center frequency of $42 \mathrm{kHz}$. Similar spectral and temporal characteristics were observed in all far-field clicks, notwithstanding the power spectra fluctuations (especially at higher frequencies) due to variations in the aspect of the clicking whales.

Far-field click recordings at sampling rates of 192 and $384 \mathrm{kHz}$ were examined to assess the adequacy of the 96 $\mathrm{kHz}$ sampling rate used in the double tag recording. Although this reduced bandwidth does not fully cover the spectrum of the clicks, it is important to determine whether it is sufficient to sample most of the click energy and therefore would yield reliable estimates of ASL and DI. Far field clicks from different whales with different recording bandwidths are compared in Fig. 3. All three clicks were selected from sequences that probably describe a scan of a Ziphius that passes the recording hydrophone; that is, within 10-20 clicks
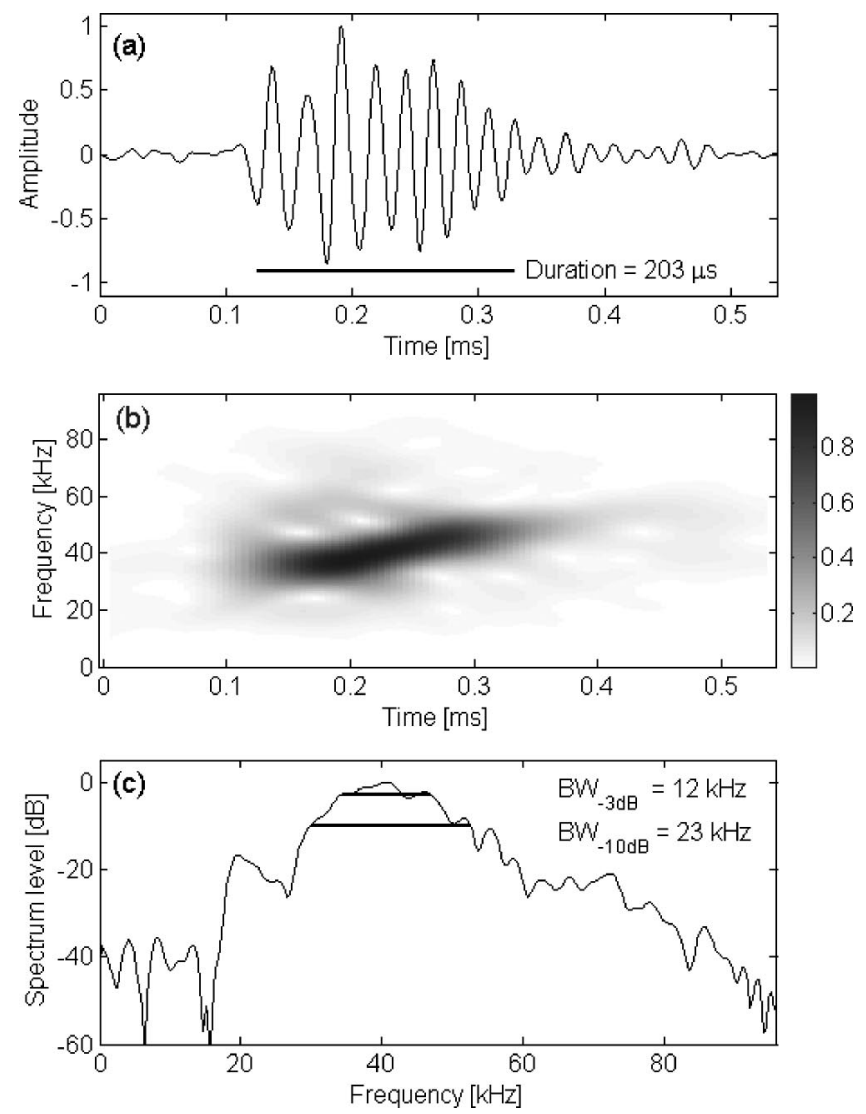

FIG. 2. Sample click of Ziphius click as received by the tag of a conspecific whale. The top panel shows the time series, the middle panel shows the spectrogram (linear spectral scale, Hann window for FFT of 32 samples, and overlap of 31 samples) and bottom panel shows the relative power spectrum. 


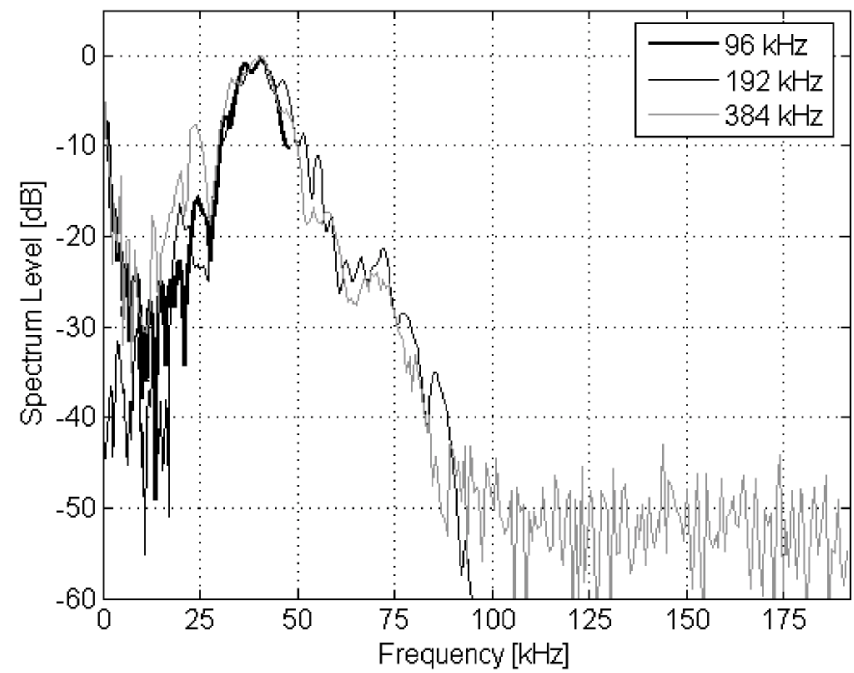

FIG. 3. Spectra of three different Ziphius clicks with three different sampling frequencies. The spectral levels are relative to the peak level at 40 $\mathrm{kHz}$.

the received signal level varied from weak to strong and to weak again. It was assumed that the click with the highest signal level was closest to the acoustic axis (sensu Møhl et al., 2003) and therefore suited for comparison. Between 26 and $60 \mathrm{kHz}$, the spectrum sampled at $192 \mathrm{kHz}$ may be fitted by a Gaussian function [Eq. (6)] with a center frequency $f_{0}=42.1 \mathrm{kHz}$ and rms bandwidth $b=7.9 \mathrm{kHz}$. Using this model, the $96 \mathrm{kHz}$ recording with a $-3 \mathrm{~dB}$ bandwidth of $47.5 \mathrm{kHz}$, samples $\sim 80 \%$ of the energy in the click and is therefore suitable for SL and DI analysis.

\section{B. Source level and directivity}

The relative orientation and range between source and receiver was estimated, prior to source level and directivity estimation.

\section{Reconstruction}

The top panel of Fig. 4 shows the reconstructed horizontal track for a simultaneous dive of both whales. It can be seen that the swimming behavior is coordinated: the two whales dived close together, moved on similar tracks while underwater, then approached each other and surfaced with a nearly parallel track. The phase selected for estimation of source level and directivity is indicated with a bolder line on both tracks. Clicks from whale A were detected during this phase on the tag attached to whale B. The bottom panel shows the range estimate from the reconstruction for this selected phase. The independent acoustic range estimates based on the travel time of clicks are overlaid and marked with dots for clicks from whale A to whale B and with triangles for clicks from whale $\mathrm{B}$ to whale $\mathrm{A}$. The ranges for the analyzed clicks vary between 400 and $100 \mathrm{~m}$.

\section{Click beam pattern}

Figure 5 shows the ASL of all clicks produced by whale $\mathrm{A}$ and received by whale $\mathrm{B}$ during the selected phase. The received level at the receiver is corrected for spherical spreading and attenuation loss. The azimuth and elevation
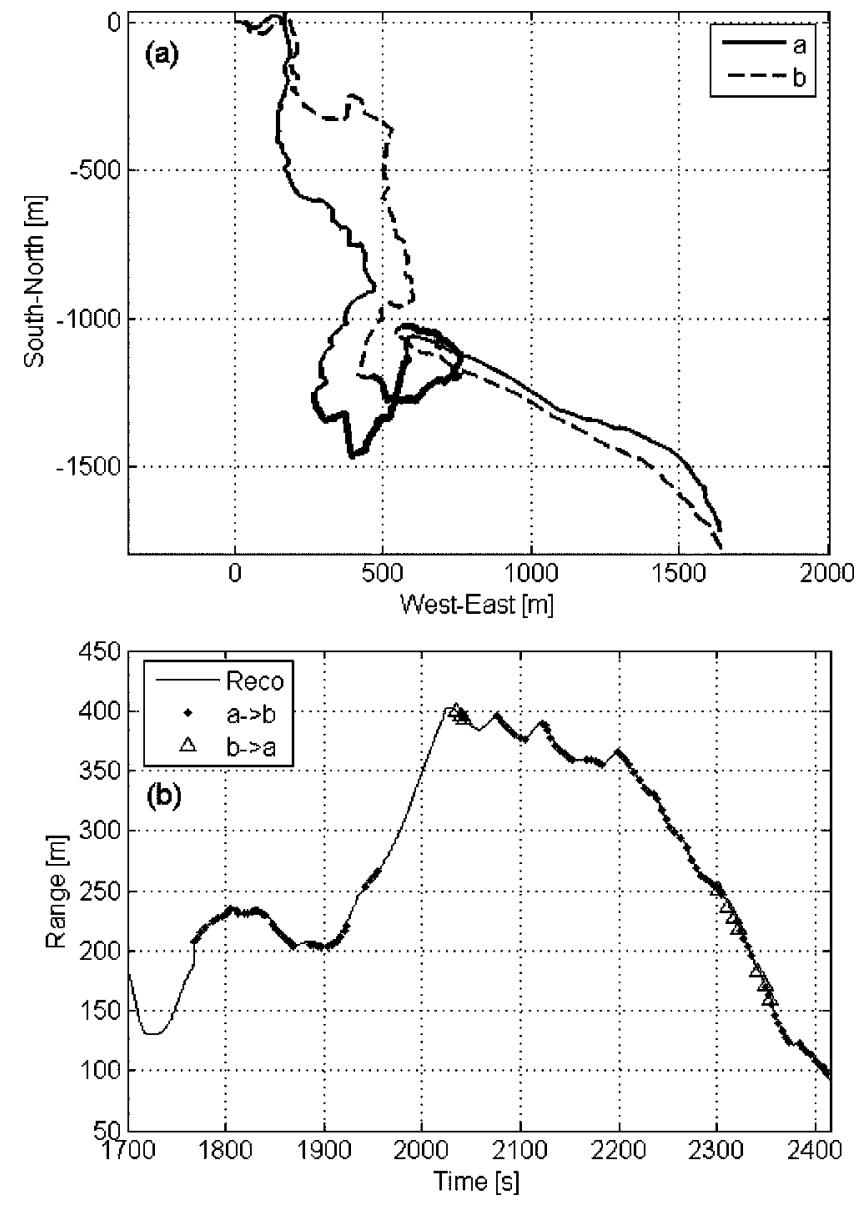

FIG. 4. Reconstruction of the tracks of two Ziphius carrying tags at the same time. Top panel: Plan view of horizontal components of tracks of whale A (solid line) and whale B (dashed line). The bold portions of the tracks mark the period when whale A approached whale B and the clicks of one tagged whale were also audible on the tag of the other whales. Bottom panel: Range between the two tagged whales. Each marker represents an acoustic range estimate; dots describe ranges for clicks emitted by whale A and received by whale $\mathrm{B}$, and triangles correspond to ranges for clicks from whale $\mathrm{B}$ that were received by whale $\mathrm{A}$.

angles of the clicking whale are plotted from the transmitter's point of view (whale A). Off-axis angles are drawn as circles around the forward orientation, i.e., where azimuth and elevation are zero. The scatter plot shows that the data available are not sufficient to describe a complete threedimensional beam pattern of the transmitted sound energy. Apart from some traces with off-axis angles $>60^{\circ}$, most clicks are received near the center with off-axis angles $<40^{\circ}$. There is considerable variation in the directions of the strongest clicks ( $>190 \mathrm{~dB}$ re: $1 \mu \mathrm{Pa})$ indicating that there is no unique and preferred direction for the click emission relative to the body axis. On the other hand, these strong clicks are isolated, which may reflect variations in the source level produced by the tagged whale as well as steering of a narrow beam by head movements altering the relation between the body axis measured by the tag and the acoustic axis of the whale.

Figure 6 shows the apparent source level (ASL) of a single scan as a function of time (left) and off-axis angle (right). A level variation of $30 \mathrm{~dB}$ during this scan makes it well suited to the estimation of source level (SL) and direc- 


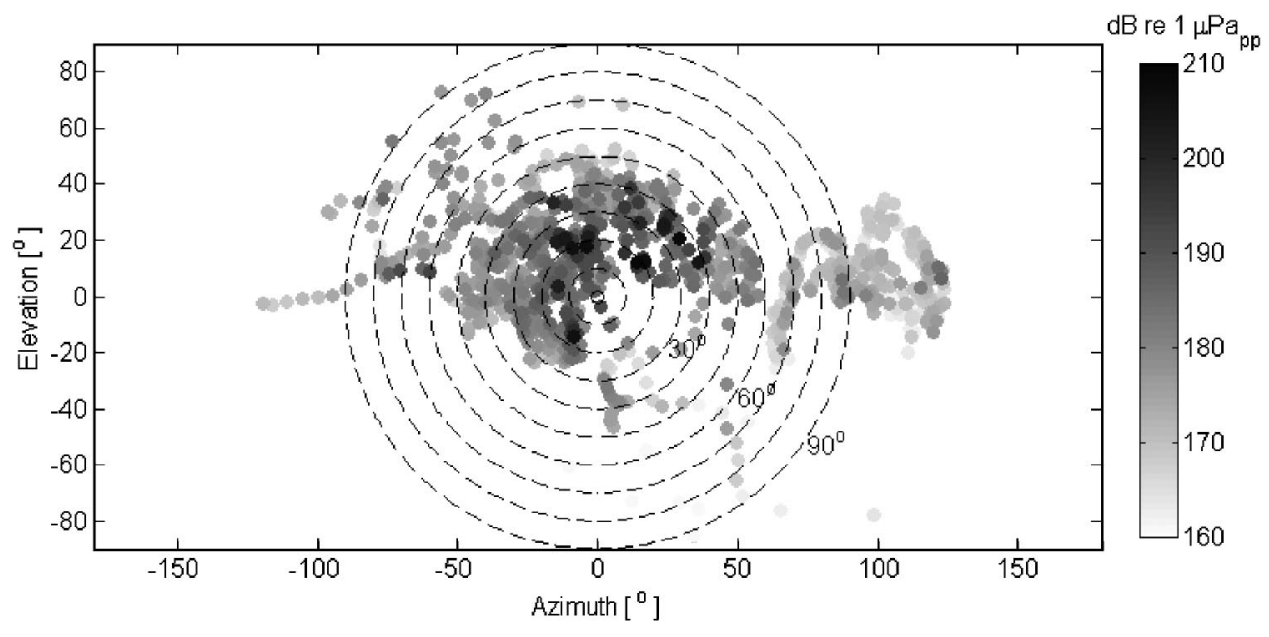

FIG. 5. Two-dimensional scatter plot of apparent source level as function of azimuth and elevation for the 1123 clicks emitted by the tagged whale and received by the companion. The angles are plotted from the transmitter's point of view. The overlaid circles correspond to the off-axis angles between the body axis of the transmitting whale and the position of the receiving whale.

tivity index (DI). Inspection of the click levels at the transmitting whale revealed a variation of less than $3 \mathrm{~dB}$ between 2074 and 2078 s, and less than 4 dB between 2078 and 2088 $\mathrm{s}$, suggesting that the source level is stable during this scan (Madsen et al., 2004). The variation in received level at the "scanned" whale is thus likely to be the result of a constant output, directional source that moves past the receiver, the maximum ASL should be a reasonable proxy for source level.

The measurements in Fig. 6 are marked by a triangle during the period of increasing received level and an asterisk during the period of decreasing received level to emphasize the asymmetry of the scan. While the decrease of the ASL ("**) coincides with an increase of the off-axis angle [marked by an open circle $(\bigcirc)$, the sharp increase ASL before its maximum cannot be explained by the off-axis angle that remains nearly constant. This is made clearer in the right panel where a broadband piston model, driven by the measured off-axis angle is superimposed. The least mean square fit of the broadband piston model to the decreasing ASL values resulted in a piston diameter $d=40 \mathrm{~cm}$, which is equivalent to a broadband directivity index $\mathrm{DI}=30 \mathrm{~dB}$ when radiating a Ziphius click [Eq. (7)], corresponding in turn to a $-3 \mathrm{~dB}$ beam width of $\Theta=6^{\circ}$ [Eq. (8)]. The modeled piston beam (marked with open circles) has its maximum at an off-axis angle of $15^{\circ}$ indicating that, for this scan, the body axis and the acoustic axis are not aligned, which may relate to head movements and a possible offset between body and acoustic axis as seen in dolphins (Au, 1993). The temporal and spectral values of the Ziphius click at the maximum of the scan are compiled in Table I, which also provides a comparison with three other echolocating toothed whales.

\section{Off-axis click distribution}

All ASL values are given again in Fig. 7, which shows in gray the ASL as a function of off-axis angle. Superimposed are the data from the single scan of Fig. 6 [marked "*"], and the modeled broadband piston beam (solid line) that was fitted to the selected scan. The piston beam not only fits the selected scan but also seems to be a fair approximation of most clicks below an ASL of $190 \mathrm{~dB}$.

\section{DISCUSSION}

\section{A. Temporal and spectral characteristics}

The echolocation clicks of Ziphius occur regularly with an ICI averaging about $0.4 \mathrm{~s}$. Short pauses are frequent and result in an asymmetric distribution of the ICI as shown in Fig. 1. If the two whales tagged are representative of the population, the sharp peak of the distribution around $0.4 \mathrm{~s}$ suggests that lengthy regular click trains $(>10 \mathrm{~s})$ with ICI less than $0.26 \mathrm{~s}$ are with $99 \%$ probability not being made by
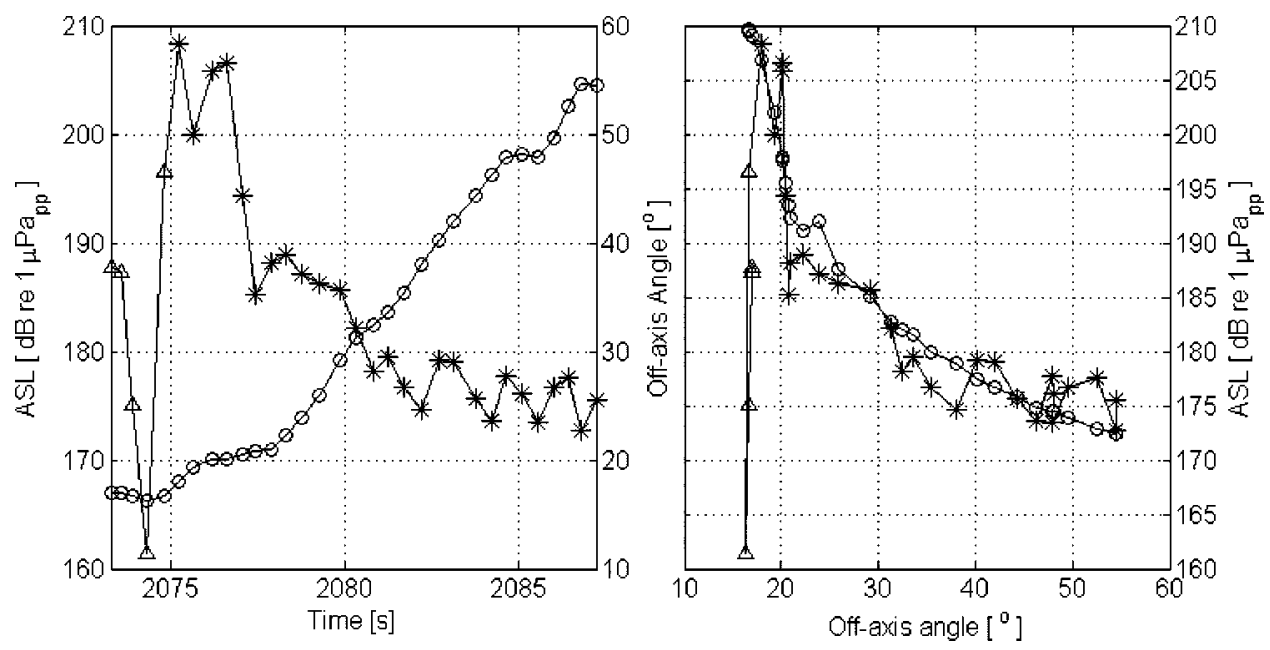

FIG. 6. Single scan of whale A as recorded by whale B. The left panel shows as function of time (a) the ASL (triangles and asterisks) and the offaxis angle (open circles). The right panel shows as function of off-axis angle (a) the ALS (triangles and asterisks) and (b) a prediction (open circles) of the ASL by a piston model. 
TABLE I. Comparison of salient parameters for the description of echolocation signals of four toothed whales, harbor porpoise (Phocoena phocoena), bottlenose dolphin (Tursiops truncatus), Cuvier's beaked whale (Ziphius cavirostris), and sperm whale (Physeter macrocephalus).

\begin{tabular}{lcccc}
\hline \hline & $\begin{array}{c}\text { Phocoena } \\
\text { (Au } \text { et al., 1999) }\end{array}$ & $\begin{array}{c}\text { Tursiops } \\
\text { (Au, 1993) }\end{array}$ & $\begin{array}{c}\text { Ziphius } \\
\text { (this paper) }\end{array}$ & $\begin{array}{c}\text { Physeter } \\
\text { Møhl } \text { et al., 2003; } \\
\text { Madsen } \text { et al., 2002) }\end{array}$ \\
\hline $\mathrm{SL}_{\mathrm{pp}}$ : $1 \mu \mathrm{Pa}$ at $\left.1 \mathrm{~m}\right]$ & 170 & 228 & $\mathbf{2 1 4}$ & 240 \\
{$[\mathrm{~dB}$ re } & & & & 195 \\
Energy flux density & 130 & 167 & $\mathbf{1 6 4}$ & 27 \\
{$\left[\mathrm{~dB}\right.$ re: $\left.1 \mu \mathrm{Pa}^{2} \mathrm{~s}\right]$} & 22 & 26 & $\mathbf{2 5 5}$ & 120 \\
DI $[\mathrm{dB}]$ & 100 & 25 & $\mathbf{2 0 0}$ & 15 \\
Duration $[\mu \mathrm{s}]$ & 130 & 120 & $\mathbf{4 0}$ & 20 \\
$F_{\text {peak }}[\mathrm{kHz}]$ & 135 & 100 & $\mathbf{4 2}$ & 10 \\
$F_{0}[\mathrm{kHz}]$ & 20 & 100 & $\mathbf{2 3}$ & 5 \\
$-10 \mathrm{~dB} \mathrm{BW}[\mathrm{kHz}]$ & 10 & 30 & $\mathbf{1 2}$ & $2-3$ \\
$-3 \mathrm{~dB} \mathrm{BW}[\mathrm{kHz}]$ & 13 & $2-3$ & $\mathbf{4}$ & \\
$Q=F p / \mathrm{BW}$ & & & & \\
\hline \hline
\end{tabular}

Ziphius, if one ignores buzzes that have ICI $\ll 0.15 \mathrm{~s}$ (Johnson et al., 2004) and are difficult to detect when recording in the far field.

The spectra of Ziphius clicks peak at $40 \mathrm{kHz}$ with $-30 \mathrm{~dB}$ points in energy ranging from 15 to $80 \mathrm{kHz}$, and -10 and $-3 \mathrm{~dB}$ bandwidths of around 23 and $12 \mathrm{kHz}$, respectively. The $Q$ of the clicks (i.e., the center frequency divided by the $-3 \mathrm{~dB}$ bandwidth) is about 4 , and is closer to that of dolphin and sperm whale clicks $(Q=2-3)$ than it is to species such as porpoise that produce monochromatic signals with $Q$ 's of more than 10 (Table I).

Representative spectra for Ziphius clicks, recorded by three different instruments between 2002 and 2004, are shown in Fig. 3. Although these clicks are almost certainly from different whales, all three spectra have a spectral peak at $40 \mathrm{kHz}$ and a spectral notch at about $26 \mathrm{kHz}$. Spectral differences above the peak frequency may indicate that the measurements were not all made precisely on the acoustic axis of the clicking whale and so may include some off-axis

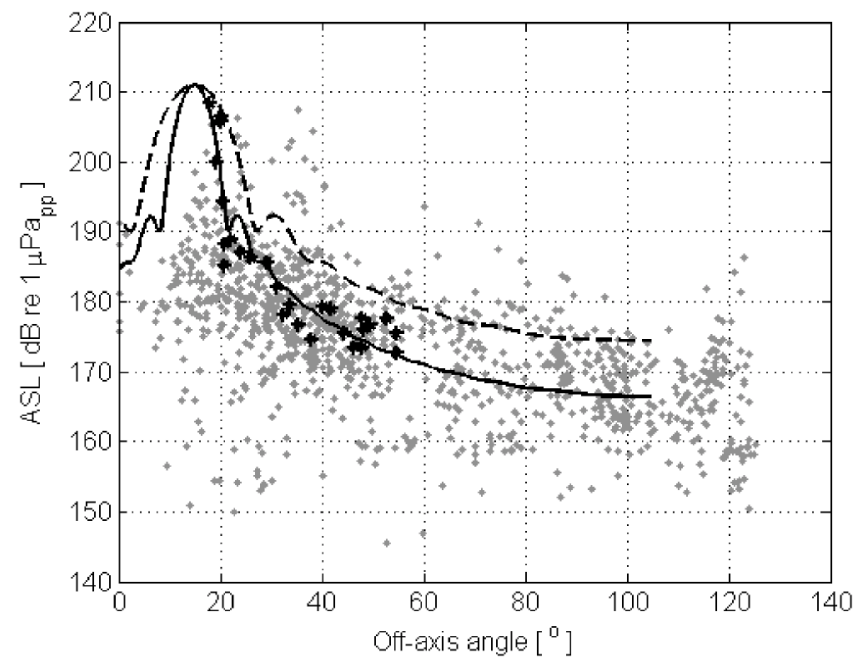

FIG. 7. The apparent source level (ASL) of 1123 clicks is plotted in gray against off-axis angle. In black are the clicks from single scan (the asterisks from Fig. 6). The solid line is the broadband beam pattern of the modeled piston with piston diameter $0.40 \mathrm{~m}$ (equivalent broadband $\mathrm{DI}=30 \mathrm{~dB}$ ), and off-axis angle of acoustic axis of $15^{\circ}$, the dashed line describes a broadband beam pattern for a $\mathrm{DI}=25 \mathrm{~dB}$. distortion ( $\mathrm{Au}, 1993)$. The features just below the $26 \mathrm{kHz}$ notch also differ for the three different plots. This may also be due to off-axis distortion, but could be a characteristic of individual whales.

The click duration of around $200 \mu$ s warrants some discussion as this is considerably longer than the duration of clicks of any non-ziphiid toothed whale. Most delphinids produce clicks with durations between 20 (Rasmussen et al., 2004) and $100 \mu \mathrm{s}$ (Au et al., 2004) so the echolocation clicks of Ziphius have a duration that is at least twice as long. The sperm whale produces multi-pulsed clicks with an overall longer duration, but the dominant P1 pulse has durations around $120 \mu \mathrm{s}$ (Møhl et al., 2003). Comparing the duration of the individual pulses that make up the sperm whale regular click, it is evident that the clicks of Ziphius are considerably longer (Table I).

Thus, the clicks of Ziphius differ from clicks recorded from delphinids and sperm whales in combining a long duration with center frequencies around $40 \mathrm{kHz}$. Killer whales (Au et al., 2004) and narwhals (Møhl et al., 1990) have similar center frequencies, but much shorter durations and lower $Q$ 's. The long click duration is a prerequisite for the frequency modulated (FM) sweep seen in Ziphius that sweeps from a frequency of about $35-45 \mathrm{kHz}$.

When comparing the click properties of Ziphius to those reported for the Northern Bottlenose whale (Hyperoodon ampulatus) by Hooker and Whitehead (2002) using a band limited $(<40 \mathrm{kHz})$ single hydrophone system, it appears that the Ziphius clicks are of higher frequency and of longer duration than clicks from the larger Hyperoodon. It is not clear if such apparent differences relate to differences in sound production, biosonar performance, size of the whale, orientation of the whales with respect to the hydrophones or simply differences in recording equipment and setup.

\section{B. Source level and directivity}

Analysis of the broadband click spectrum shows that the sampling rate of the double tag data, $96 \mathrm{kHz}$, is suitable for estimating source level and directivity index. To obtain source level (SL) and directivity index (DI), the angle of the receiver with respect to the acoustic axis (the "off-axis 
angle") must be estimated for each click. However, the offaxis angle, as derived from the tag data, is really the angle between the joining line to the receiver and the direction of motion of the clicking whale. While it cannot be excluded that the whale swam with a pitch offset, it has been assumed that the mean body axis is parallel to the mean direction of motion, so that the body axis is on average parallel to the mean swim direction. However, it seems most likely that the whale, while clicking, is moving the head and thereby the acoustic axis, separately from the body axis. This notion is supported by visual observations of whales at the surface and by anatomical evidence based on a pivot point at the occipital condyles/atlas-axis and partly unfused cervicals (Allen and Mead, private communication) suggesting that Ziphius has ample room for head motion while clicking. Finally, the authors have observed significant head movements in another beaked whale species (Mesoplodon densirostris) while clicking, supporting the notion that this is also likely the case in Ziphius.

Figure 7 has a striking lack of clicks recorded at off-axis body angles $<10^{\circ}$ whereas most strong values (ASL $>190 \mathrm{~dB}$ re: $1 \mu \mathrm{Pa}$ ) are between $15^{\circ}$ and $40^{\circ}$. From Fig. 5 it may be deduced that the measurements do not cover all aspects (e.g., there are no data for azimuth $10^{\circ}-30^{\circ}$ and elevation $0^{\circ}-20^{\circ}$ ) and that the strong clicks are scattered around the forward direction. Accordingly, some of the scatter in the data of Figs. 5 and 7 is likely the result of head movements by the clicking whale. Likewise the lack of recorded clicks from off axis body angles $<10^{\circ}$ may be a consequence of inadequate sampling. The increasing part of the selected scan, marked by triangles in Fig. 6, appears to be independent of the off-axis angle variation due to body motion, suggesting that the increase in level represents a head scan. The sharp increase of the received level during this apparent scan suggests that excursion of the head movement is at least $25^{\circ}$ with a scan rate of $25^{\circ} / \mathrm{s}$, which is consistent with observations of Frantzis et al. (2002). The correlation of ASL with body axis during the decreasing part of the scan (marked "*") suggests that body motion dominates this effect.

The highest ASL levels are the best candidates for defining the maximum source level (SL) of this species. The highest measured SL of $214 \mathrm{~dB}_{\mathrm{pp}} r e: 1 \mu \mathrm{Pa}$ at $1 \mathrm{~m}$ is considerably lower than the maximum levels of more than $220 \mathrm{~dB}_{\mathrm{pp}}$ re: $1 \mu \mathrm{Pa}$ at $1 \mathrm{~m}$ reported for a range of dolphin species (Au, 1993) and at least $20 \mathrm{~dB}$ lower than the SL of sperm whale clicks (Møhl et al., 2003; Zimmer et al., 2005). Although it is possible that Ziphius cannot produce higher SLs, it is more likely that the full capabilities of Ziphius are underestimated here. The data set of 1123 measurements from a single dive may also represent a biased data set for SL estimation. A potential problem with using tags to measure the SL of clicks from conspecifics is that whales may avoid ensonifying each other with high-powered clicks as has been suggested for spinner dolphins (Brownlee and Norris, 1994). Thus, the maximum of $214 \mathrm{~dB}_{\mathrm{pp}}$ re: $1 \mu \mathrm{Pa}$ at $1 \mathrm{~m}$ may simply be the result of the whales reducing the volume when ensonifying each other.

The longer duration of Ziphius clicks means that they carry more energy than the clicks of other odontocete species with the same peak-to-peak sound pressure level. The observed energy flux of up to $164 \mathrm{~dB}$ re: $1 \mu \mathrm{Pa}^{2} \mathrm{~s}$ in Ziphius clicks is comparable with the energy flux of clicks of the bottlenose dolphin (Tursiops truncatus), even though the measured Ziphius source sound pressure level of $214 \mathrm{~dB}_{\mathrm{pp}}$ re: $1 \mu \mathrm{Pa}$ at $1 \mathrm{~m}$ is about $15 \mathrm{~dB}$ less than the maximum SL of Tursiops clicks (Au, 1993).

Au et al. (1999) proposed how DI might scale in toothed whales. According to this scaling, a Ziphius with head diameter at the blowhole of $60 \mathrm{~cm}$ (Allen and Mead, private communication) and a wavelength of $3.3 \mathrm{~cm}$ should have a (narrowband) $\mathrm{DI}$ of $24.3 \mathrm{~dB}$, and $-3 \mathrm{~dB}$ beam width of $12.6^{\circ}$. A similar figure is obtained by scaling the results reported by Au et al. (1995) for the DI of a false killer whale Pseudorca crassidens with a head diameter of $40 \mathrm{~cm}$ (measured DI of $22.3 \mathrm{~dB}$ at $44.3 \mathrm{kHz}$ ). Making the crude assumption that the diameter of the head at the eye scales with the transmitting aperture, we estimate that a Ziphius with a head diameter of $60 \mathrm{~cm}$ will have a (narrowband) DI of 22.3 $+20 \log (60 / 40 \mathrm{~cm})=25.8 \mathrm{~dB}$ around $40 \mathrm{kHz}$, which is about the same as the DI of Tursiops clicks radiating from a smaller equivalent aperture, but at a higher frequency. The estimated DI's are about $4-6 \mathrm{~dB}$ less than the $30 \mathrm{~dB}$ DI derived here using a broadband piston model to fit the measured ASL pattern. It is possible that our DI is an overestimation based on the assumption that the variation in ASL is only due to the angle from the body axis. Ziphius appear to move their heads regularly while searching for prey and some head motion cannot be excluded in the selected data segment. Based on the above-noted predictions and the data presented here, it seems reasonable to suggest that Ziphius clicks are radiated with a broadband DI of more than $25 \mathrm{~dB}$. Curves for $\mathrm{DI}=25 \mathrm{~dB}$ and $30 \mathrm{~dB}$ are shown in Fig. 7 and appear to bracket the data fairly well.

In conclusion, we have demonstrated that Ziphius produce ultrasonic echolocation clicks with center frequencies around $42 \mathrm{kHz}$ and the distinctive form of a FM up-sweep. The derived directivity index of $30 \mathrm{~dB}$ is a little higher than predictions based on other toothed whales, but may be a slight overestimation. The maximum SL of $214 \mathrm{~dB}_{\mathrm{pp}}$ re: 1 $\mu \mathrm{Pa}$ at $1 \mathrm{~m}$ is probably an underestimate. The clicks have a longer duration than clicks from other non-ziphiid toothed whales. The estimated energy flux density of $164 \mathrm{~dB}$ re: $1 \mu \mathrm{Pa}^{2} \mathrm{~s}$ is comparable to that of clicks from bottlenose dolphins, which have considerably higher peak-to-peak sound pressures. It is thus evident that Ziphius produce clicks with temporal and spectral properties that differ from those of clicks produced by most other toothed whales, and that the clicks, on that basis, hold a potential for acoustic classification and passive monitoring.

\section{ACKNOWLEDGMENTS}

The authors thank D. Allen and J. Mead from the Smithsonian Institution, DC for providing insights on the anatomy of beaked whales and B. Møhl and M. Wahlberg for providing helpful critique on earlier versions of the manuscript. We also thank the following for fieldwork assistance: N. Aguilar de Soto, M. Ballardini, A. Bocconcelli, J. F. Borsani, I. Ca- 
varetta, T. Pusser, E. Revelli, and A. Sturlese. Tag development was assisted by T. Hurst, K. Shorter, K. Barton and funded in part by a Cecil H. and Ida M. Green Award and the US Office of Naval Research. WHOI fieldwork and tag development was funded by the National Oceanographic Partnership Program (NOPP), the Strategic Environmental Research and Development Program (SERDP) under Program No. CS-1188, and the Packard Foundation, and was supported by BluWest and the NATO Undersea Research Center. The whales were tagged under US National Marine Fisheries Service research Permit No, 981-1578-02 and 981-1707-00 to Peter L. Tyack and the research was approved by the Woods Hole Oceanographic Institution Animal Care and Use Committee. This is Contribution No 11270 from the Woods Hole Oceanographic Institution.

Au, W. W. L. (1993). The Sonar of Dolphins (Springer, New York).

$\mathrm{Au}, \mathrm{W}$. W. L. (1997). "Echolocation in dolphins with a dolphin-bat comparison," Bioacoustics 8, 137-162.

Au, W. W. L., Floyd, R. W., Penner, R. J., and Murchison, E. (1974). "Measurements of echolocation signals of the Atlantic bottlenose dolphin, Tursiops truncatus Montagu, in open waters," J. Acoust. Soc. Am. 56, 12801290.

Au, W. W. L., Ford, J. K. B., Horne, J. K., and Newman Allman, K. A. (2004). "Echolocation signals of free-ranging killer whales (Orcinus orca) and modelling of foraging for Chinook salmon (Oncorhynchus tshawytscha)," J. Acoust. Soc. Am. 115, 901-909.

$\mathrm{Au}, \mathrm{W}$. W. L., and Herzing, D. L. (2003). "Echolocation signals of wild Atlantic spotted dolphin (Stenella frontalis)," J. Acoust. Soc. Am. 113, $598-604$.

Au, W. W. L., Kastelein, R. A., Rippe, T., and Schooneman, N. M. (1999). "Transmission beam pattern and echolocation signals of a harbor porpoise (Phocoena phocoena)," J. Acoust. Soc. Am. 106, 3699-3705.

Au, W. W. L., Moore, P. W., and Pawloski, D. (1986). "Echolocation transmitting beam of the Atlantic bottlenose dolphin," J. Acoust. Soc. Am. 80, 688-691.

Au, W. W. L., Pawloski, J. L., Nachtigall, P. E., Blonz, M., and Gisner, R. C. (1995). "Echolocation signals and transmission beam pattern of a false killer whale (Pseudorca crassidens)," J. Acoust. Soc. Am. 98, 51-59.

Brownlee, S. M. and Norris, K. S. (1994). "The acoustic domain," in The Hawaiian Spinner Dolphin, edited by K. S. Norris, B. Würsig, R. S. Wells, and M. Würsig (University of California Press, Berkeley), pp. 161-185.

Caldwell, D. K., and Caldwell, M. C. (1971). "Sounds produced by two rare cetaceans stranded in Florida," Cetology 4, 1-6.

Dawson, S. M., Barlow, J., and Ljungblad, D. K. (1998). "Sounds recorded from Baird's beaked whales Berardius bairdii." Marine Mammal Sci. 14, 335-344.

Frantzis, A. (1998). "Does acoustic testing strand whales?" Nature (London) 392, 29.

Frantzis, A., Goold, J. C., Sharsoulis, E. K., Taroudakis, M. I., and Kandia, V. (2002). "Clicks from Cuvier's beaked whales, Ziphius cavirostris (L)," J. Acoust. Soc. Am. 112, 34-37.

Hooker, S. K., and Whitehead, H. (2002). "Click characteristics of northern bottlenose whales (Hyperoodon ampullatus)," Marine Mammal Sci. 18, $69-80$.

Jazwinski, A. H. (1970). Stochastic Processing and Filtering Theory (Academic, New York)

Jepson, P. D. et al. (2003). "Gas-bubble lesions in stranded cetaceans," Nature (London) 425, 575-576.

Johnson, M., Madsen, P. T., Zimmer, W. M. X., Aguilar de Soto, N., and Tyack, P. L. (2004). "Beaked whales echolocate on prey," Proc. R. Soc. London, Ser. B 271, S383-S386.

Johnson, M., and Tyack, P. L. (2003). "A digital acoustic recording tag for measuring the response of wild marine mammals to sound," IEEE J. Ocean. Eng. 28, 3-12.

Lurton, X. (2002). An Introduction to Underwater Acoustics (Springer, London), $347 \mathrm{pp}$.

Lynn, S. K., and Reiss, D. L. (1992). "Pulse sequence and whistle production by two captive beaked whales, Mesoplodon species," Marine Mammal Sci. 8, 299-305.

Madsen, P. T., Wahlber, M., and Møhl, B. (2002). "Male sperm whale (Physeter macrocephalus) acoustics in a high latitude habitat: implications for echolocation and communication," Behav. Ecol. Sociobiol. 53, 31-41.

Madsen, P. T., Kerr, I., and Payne, R. (2004). "Echolocation clicks of two free-ranging, oceanic delphinids with different food preferences: False killer whales (Pseudorca crassidens) and Risso's dolphins (Grampus griseus)," J. Exp. Biol. 207, 1811-1823.

Marten, K. (2000). "Ultrasonic analysis of pygmy sperm whale (Kogia breviceps) and Hubb's beaked whale (Mesoplodon carlhubbsi) clicks," Aquat. Mamm. 1, 45-48.

Møhl, B., Surlykke, A., and Miller, L. A. (1990). "High intensity narwhal click," in Sensory Abilities of Cetaceans, edited by J. Thomas and R. Kastelein (Plenum, New York), pp. 295-304.

Møhl, B., Wahlberg, M., Madsen, P. T., Heerfordt, A., and Lund, A. (2003). "The monopulsed nature of sperm whale clicks," J. Acoust. Soc. Am. 114, $1143-1154$.

Møhl, B., Wahlberg, M., Madsen, P. T., Miller, L. A., and Surlykke, A. (2000). "Sperm whale clicks: Directionality and source level revisited," J. Acoust. Soc. Am. 107, 638-648.

Rasmussen, M. H., Wahlberg, M., and Miller, L. (2004). "Estimated transmission beam pattern of clicks recorded from free-ranging white-beaked dolphins (Lagenorhyncus albirostris)," J. Acoust. Soc. Am. 116, 18261831

Rice, D. W. (1998). Marine Mammals of the World, Systematics and Distribution (The Society for Marine Mammology, Allen Press, Lawrence).

Schotten, M., Au, W. W. L., Lammers, M. O., and Aubauer, R. (2003). "Echolocation recordings and localization of wild spinner dolphins (Stenella longirostris) and pantropical spotted dolphins (Stenella attenuata) using a four-hydrophone array," in Echolocation in Bats and Dolphins, edited by J. Thomas, C. F. Moss, and M. Vater (University of Chicago Press, Chicago), pp. 383-400.

Simmonds, M. P., and Lopez-Jurado, L. F. (1991). "Whales and the military," Nature (London) 337, 448.

Zimmer, W. M. X., Johnson, M. P., D’Amico, A., and Tyack, P. L. (2003). "Combining data from a multi-sensor tag and passive sonar to determine the diving behavior of a sperm whale (Physeter macrocephalus)," IEEE J. Ocean. Eng. 28, 13-28.

Zimmer, W. M. X., Tyack, P. L., Johnson, M. P., and Madsen, P. T. (2005). "Three-dimensional beam pattern of regular sperm whale clicks confirms bent-horn hypothesis," J. Acoust. Soc. Am. 117, 1473-1485. 